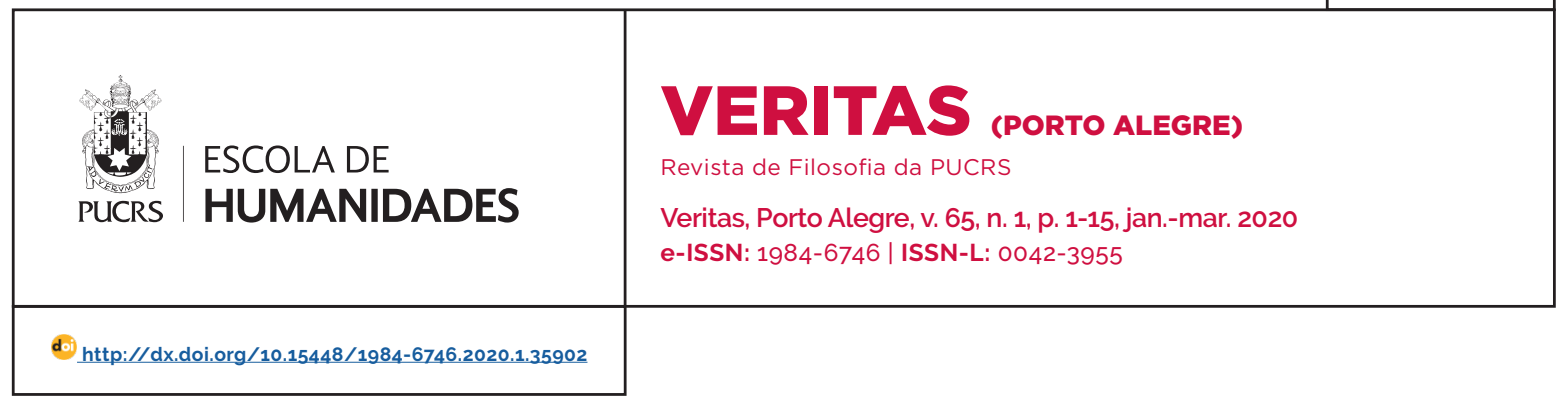

SEÇÃO: MORAL \& POLITICAL PHILOSOPHY

\title{
Canguilhem: saúde, doença e norma
}

\author{
Canguilhelm: health, disease and norm \\ Canguilhem: salud, enfermedad y norma
}

\section{Alysson Leandro \\ Mascaro ${ }^{1}$ \\ orcid.org/0000-0003-3641-3053 alysson@mascaro.adv.br}

Recebido em: 10 jun. 2019.

Aprovado em: 15 dez. 2019. Publicado em: 12 mai. 2020
Resumo: A relação entre o vital e o social no pensamento de Georges Canguilhem envolve uma especifica reestruturação filosófica, por ele empreendida em O normal e patológico, realizando um deslocamento teórico em face das análises quantitativas da saúde quanto, ao mesmo tempo, construindo uma problemática própria a respeito da normação, fazendo com que o vital seja pensado, inexoravelmente. como a imbricação do biológico com o social, acarretando, ainda, um reposicionamento político, crítico, no que tange à consideração sobre saúde e doença.

Palavras-chave: Canguilhem. Filosofia da saúde. Vital e social. Norma.

Abstract: The relationship between vital and social in Georges Canguilhem's thinking involves a specific philosophical restructuring, undertook in The Normal and Pathological, making a theoretical shift that opposes quantitative health analyzes. At the same time, he constructs his own problematic concerning normalization, thinking the vital being, inexorably, as an imbrication of biological and social, causing, also, a political, critical repositioning, regarding the consideration of health and disease. Keywords: Canguilhem, Philosophy of health. Vital and social. Norm.

Resumen: La relación entre lo vital y lo social en el pensamiento de Georges Canguilhem implica una reestructuración filosófica especifica, emprendida por él en Normal y Patológica, realizando un desplazamiento teórico frente a los análisis cuantitativos de salud, cuanto, al mismo tiempo, la construcción de su propio problema con respecto a la norma, haciendo que lo vital sea pensado, inexorablemente, como la inbricación de lo biológico con lo social, causando también un reposicionamiento político, crítico, con respecto a la consideración sobre la salud y la enfermedad.

Palabras clave: Canguilhem. Filosofía de la salud. Vital y social. Norma.

\section{Introdução}

A filosofia da saúde no século XX tem em Georges Canguilhem seu pensador fulcral. Partilhando do epicentro dos debates franceses, sua plataforma teórica e sua dupla formação, em filosofia e medicina, permitiuIhe avançar com especial propriedade na interrelação dos dois âmbitos. ${ }^{2}$ O percurso da obra de Canguilhem se inicia com textos concernentes à sua primeira formação, filosófica, na década de 1930, e depois, a partir dos anos 1940, já com suas reflexões acerca da medicina e da saúde, que se estendem, em décadas posteriores, a questões das ciências da vida,

1 Universidade de São Paulo (USP), São Paulo, SP. Brasil.

"Canguilhem ne s'intéresse donc pas à la médecine en tant que médecin, pour la médecine; pas davantage en tant qu'historien de la médecine : c'est en philosophe qu'il l'aborde. [...] Il a, de fait, jugé que la médecine était, parmi toutes ces matières, la meilleure qu'il pouvait choisir dans le prolongement de ses études philosophiques. Fauit-il alors le tenir pour un philosophe de la médecine? En un sens oui, et les textes récemment publiés sous le titre d'Écrits sur la médecine montrent bien une attention constante aux évolutions de cette « matière » choisie à la fin des annés 1930, et ce jusqu'en 1989. Il faut ajouter que les sciences du vivant, auxquelles il n'a cessé de consacrer des réflexions, ont la part belle dans les recueils qu'il a lui-même composés pour publication. Ces sciences n'y sont en définitive le plus souvent envisagées que dans leurs rapports complexes à la médecine." LECOURT, Dominique. Georges Canguilhem. Paris: PUF, 2008, p. 33. 
como a biologia, e também a problemas como o da ciência e da técnica. Destacam-se, nesse trajeto intelectual, obras como O conhecimento da vida, Estudos de história e de filosofia das ciências e Ideologia e racionalidade nas ciências da vida. que ecoam e desenvolvem questões de seu livro mais conhecido, O normal e o patológico, onde Canguilhem indaga acerca da natureza da saúde e da doença, propondo temáticas e abordagens bastante próprias. Mergulhar esta obra numa perspectiva social é perfilhá-la como ponta de lança da melhor tradição filosófica crítica. Questões como a da norma, do normal e da normação resultarão outras, retificadas e ampliadas, com as propostas de Canguilhem.

\section{0 debate de Canguilhem}

A obra principal de Georges Canguilhem tem por base, originalmente, sua tese de doutorado em medicina defendida em 1943, em pleno desenrolar da guerra, ${ }^{2}$ intitulada "Ensaio sobre alguns problemas relativos ao normal e ao patológico". Na década de 1960, provocado também pelas ideias de seu discipulo Michel Foucault, Canguilhem acrescenta à tese o texto "Novas reflexões referentes ao normal e ao patológico", dando então título, à obra daí resultante, de O normal e o patológico, publicada em 1966.

Se este livro abre um campo próprio na reflexão sobre saúde, o faz, no entanto, a partir de um diálogo crítico com saberes anteriormente assentados. Georges Canguilhem chama ao cotejo, em especial, Auguste Comte, Claude Bernard e, em outra chave, René Leriche; o primeiro filósofo e cientista social, os demais médicos. Para tais pensadores - e corrente desde o século XIX - está a ideia de que entre doença e saúde não se dá uma distinção qualitativa, mas meramente quantitativa. Contra velhas visões médicas que imaginavam a doença como entidade extrafisiológica - ou mesmo como "mal", tomado de modo quase metafísico e em oposição à boa saúde corporal -, os estados saudável e patológico se submetem à mesma natureza e às mesmas leis, diferindo, então, nas proporções ou nas variações que levam o corpo a se manter são ou a adoecer. É levantando essa base identitária entre saúde e doença e em face dela que, posteriormente, a proposta de Canguilhem se insurgirá:

A identidade real dos fenômenos vitais normais e patológicos, aparentemente tão diferentes e aos quais a experiência humana atribui valores opostos, tornou-se, durante o século XIX, uma espécie de dogma, cientificamente garantido. cuja extensão no campo da filosofia e da psicologia parecia determinada pela autoridade que os biólogos e os médicos the reconheciam. Na França, esse dogma foi exposto, em condições e de acordo com intenções bem diferentes, por Augusto Comte e Claude Bernard. Na doutrina de Comte, é uma ideia que - explicita e respeitosamente - ele reconhece dever a Broussais. Em Claude Bernard, é a conclusão tirada de uma vida inteira de experimentação biológica e cuja prática é codificada metodicamente pela célebre Introduction à l'étude de la médecine expérimentale. ${ }^{3}$

A busca por Auguste Comte para iniciar a reflexão sobre saúde e doença se deve, para Canguilhem, pelo impacto do pensamento comteano nas ciências do século XIX, em especial na medicina. Comte tinha alguma formação e destacado interesse na biologia, resultando dai sua tentativa de fundar categorias da filosofia positiva naquelas biológicas. ${ }^{4}$ Sua proposição de identidade entre os fenômenos

\footnotetext{
2 Canguilhem engaja-se na luta de resistência ao governo de Vichy e à dominação nazista na França. No plano teórico, já desde a década de 1930 apresenta reflexões críticas ao fascismo: "L'alliance contre la tyrannie fasciste exige um double choix. Par les partis ouvriers, le choix loyal de la paysannerie à défendre pour elle-même et pour sa valeur humaine. Par les paysans, le choix résolu de la classe ouvrière à libérer pour elle-même et pour un commun avenir de justice. Puisse cette bien maigre étude susciter en quelques-uns la conscience qu'une action urgente pourrait encore déterminer ce double choix et permettre, chez nous et ailleurs, l'accomplissement de ce vœu : une humanité libre, réconciliée avec la terre, autrement que dans la tombe et par la mort." CANGUILHEM, Georges. "Le fascisme et les paysans". OEuvres complètes. Vol. I. Écrits philosophiques et politiques (1926-1939). Paris: Vrin, 2011, p. 571.

3 CANGUILHEM, Georges. O normal e o patológico. Rio de Janeiro: Forense Universitária, 2015, p. 13.

4 "A assimilação - implícita - do biológico ao social, e a redução - explícita - do social ao biológico, é o ponto chave do jogo, de natureza ideológica, de justificação de uma ordem social em nome da ordem natural, objetiva, que é, ela, previamente e implicitamente investida, ao nível biológico, de fins e valores sociais e humanos. [...] A filosofia médica de Comte assume um cunho ideológico, na medida em que ele se apoia sobre a medicina em seu projeto de fundação de uma ciência social. O problema social aparece como o análogo do problema médico, ao nivel macroscópico. A harmonia entre o corpo e o cérebro, entre o físico e o moral é o protótipo da harmonia procurada entre o poder temporal e o poder espiritual". CARRION, Rejane. A ideologia médico-social no sistema de A. Comte. Porto Alegre: IFCH-UFRGS, 1977, p. 44, 79.
} 
patológicos e fisiológicos é diretamente baseada em François Broussais, médico francês do início do século XIX, para quem as doenças se devem a excessos ou carências de excitação dos tecidos, em graus maiores ou menores do que aquele que seja o normal e, portanto, saudável. Lastreando-se nessa proposta de Broussais - que Canguilhem faz remontar, na verdade, ao francês Xavier Bichat e ao inglês John Brown ${ }^{5}$ como seus construtores primeiros -, Comte procura estabelecer uma dinâmica da política social que consiga ser sustentada por uma estática social. A ordem social é a medida que não extrapola, tal qual a saúde é uma questão de variação quantitativa em face da doença. ${ }^{6}$

Claude Bernard, o médico e cientista francês elevado às glórias científicas da segunda metade do século XIX, propugna uma leitura sobre saúde e doença a partir de suas pesquisas e de seu afazer de médico, diferenciando-se assim de Comte, que dos temas erigia uma leitura eminentemente filosófica. Para Bernard, o estudo da fisiologia, compreendendo o saudável, carreava a possibilidade de saber a respeito do patológico, esse do campo da medicina. Sua plataforma de reflexão reconhece uma identidade entre o saudável e o doente, fazendo diferir ambos por conta da variação quantitativa.? Trabalhando a partir de pesquisas concretas como a que empreendeu em torno do diabetes, Bernard chega a reconhecer algumas distinções qualitativas dos fenômenos patológicos em relação aos fisiológicos, mas seu quadro geral de pensamento opera em termos de uma continuidade real entre eles. ${ }^{8}$ Em sua opinião, tal qual não há duas químicas, a do laboratório e a da vida, tal qual não há diferença de leis entre o mineral e o orgânico ou entre o vegetal e o animal - embora para ele haja, claramente, uma expressão peculiar dos fenômenos em cada situação ou corpo, daí seu conceito de meio interno e sua autonomia relativa em face do meio externo, que será proposto posteriormente como homeostase -, assim também a doença será tomada como expressão exagerada ou diminuida de uma função normal.

Nesse inventário de Canguilhem, ocupa posição própria o pensamento de René Leriche, já no século XX, cuja análise propugna ser a saúde a vida no silêncio dos órgãos, enquanto a doença seria a perturbação do exercício normal da vida do doente, aquilo que o faz sofrer. Disso resulta que. para Leriche, não basta apenas o ponto de vista do doente para definir cientificamente a doença: somando-se à consciência do ser humano, é necessário o trabalho a partir da ciência do médico, no que se reafirmaria a identidade entre saúde e doença pelo ângulo científico. ${ }^{9}$ Ocorre que, se a benefício do paciente, dever-se-ia desumanizar a ciência, então o que menos importaria seria o homem. Os estudos de Leriche sobre a dor, preocupação que o notabilizou, revelam a difícil

\footnotetext{
5 "Embora tenha visto na irritação o mal, em vez de, tal como Brown, ver na estimulação o remédio, Broussais conservou o princípio da identidade dos fenômenos orgânicos normais e patológicos, considerados em niveis de intensidade aproximados. Este principio, que abolia a distinção entre patologia e fisiologia, foi admitido por Magendie, por Auguste Comte e por Claude Bernard. Para este último, e para outros, este princípio fundou uma ideologia, a ideologia do poder ilimitado da medicina, uma ideologia médica liberta de qualquer espécie de fidelidade ao hipocratismo". CANGUILHEM, Georges. Ideologia e racionalidade nas ciências da vida. Lisboa: Edições 70, 1977, p. 48. 6 "Tudo o que rompe o equilibrio, que é o estado normal da espécie, só pode ser patológico, e definido como atrofia ou hipertrofia das funções no organismo sadio". COELHO, Ruy. Individuo e sociedade na teoria de Auguste Comte. São Paulo: Perspectiva: CESA, 2005, p. 77. 7 "Nous ne saurions établir aucune distinction fondée entre les méthodes d'investigation que l'on doit appliquer en physiologie, en pathologie et en thérapeutique. C'est toujours la même méthode d'observation et d'expérimentation immuable dans ses principes, offrant seulement quelques particularités dans l'application suivant la complexité relative des phénomènes. Nous ne saurions trouver, en effet, aucune différence radicale entre la nature des phénomènes physiologiques, pathologiques et thérapeutiques. Tous ces phénomènes dérivent de lois qui, étant propres à la matière vivante, sont identiques dans leur essence et ne varient que par les conditions diverses dans lesquelles les phénomènes se manifestent". BERNARD, Claude. Introduction à l'étude de la médecine expérimentale. Paris: Flammarion, 2010, p. 250.

8 "Para Bernard, uma explicação causal em fisiologia aponta as condições materiais (fisicoquimicas) próximas dos acontecimentos biológicos. Mas as leis fisiológicas descrevem fenômenos da organização que não podem conceitualmente ser reduzidos a fenômenos fisicoquímicos". DUTRA, Luiz Henrique de Araújo. Claude Bernard, o vitalismo e o materialismo. In: RUSSO, Marisa; CAPONI, Sandra (org.). Estudos de filosofia e história das ciências biomédicas. São Paulo: Discurso Editorial, 2006. p. 160.

9 "Faire de la thérapeutique, c'est chercher à supprimer la maladie elle-même, ou ses symptômes. Le traitement est un acte qui tend à mettre un point final au chapitre de pathologie vécu par le malade. Evidemment, nous voyons bien l'homme en lui. Nous compatissons Nous réconfortons. Nous sommes humains. Mais du fait de notre éducation plus livresque qu'humaine, le malade devient facilement un cas. Par déformation professionnelle, nous sommes portés à oublier, devant l'intérêt pathologique, l'homme dans sa vie, au centre de son propre univers, individuel, familial, social. Dès que la maladie est supprimée dans ses manifestations ou dans sa cause, nous sommes satisfaits comme si rien de plus ne pouvait nous être demandé. Je pense que nous devons quelque chose de plus... Dans nos statistiques, à côté de la colonne où le résultat s'exprime en fonction de la maladie, nous devrions introduire la rubrique de la valeur humaine de nos opérations. Nous devrions chercher si l'opéré est vraiment satisfait de l'état nouveau que nous lui avons donné. Car s'il ne l'est pas, pouvons-nous le dire guéri?" LERICHE, René. L'idée de l'Homme dans la thérapeutique. In: CLARKE, Robert (org.). René Leriche ou l'humanisme en chirurgie. Paris: Seghers, 1962. p. 155.
} 
compatibilização entre um saber cientifico externo ao paciente e os estados de sofrimento pessoal. ${ }^{10}$ Georges Canguilhem vê as variações de pensamento entre Comte, Bernard e Leriche como devidas aos seus próprios modelos de abordagem, no que resultará, então, uma reflexão acerca das suas caminhadas metodológicas para compreender saúde e doença. Sobre a relação entre fisiologia e patologia, Comte trabalha com a perspectiva de filósofo; Bernard, a partir de uma visão de cientista; Leriche, a partir de um julgamento de técnico. Comte e Bernard, de modo positivista, consideram a técnica como a aplicação de uma ciência. Leriche, por sua vez, considera a técnica médica e cirúrgica, conclamada pela doença, o caminho para a chegada à ciência. Comte e Leriche fazem, em suas teorias, um trajeto que vai do patológico ao fisiológico, mas o primeiro assim o faz para fixar o normal como ciência da ordem, e o segundo para fazer da fisiologia um sustentáculo para a cura do patológico. Bernard, por sua vez, partindo do fisiológico ao patológico, caminha em estrada oposta à de Comte para chegar à mesma consagração da ciência como esclarecedora de todos seus fenômenos variantes.

Após o balanço da relação entre filosofia, ciência e técnica em pensadores que the foram anteriores, Canguilhem, a partir da valorização da técnica ${ }^{11}$ e da clínica, abrirá seu próprio caminho de reflexão sobre saúde e doença.

\section{0 normal e o patológico}

A filosofia de Georges Canguilhem empreende um deslocamento da questão da saúde e da doença, afastando-a do problema da sua fixação a partir de mensurações de quantidade. Será na qualidade de saudável e de doente que repousará sua reflexão. Dessa nova chave, levantam-se problemas especificos: para Canguilhem, existe uma polaridade vital, apresentando-se como seu contraste a doença. Seja na saúde ou na doença, a vida tem normatividade, o que faz com que o ser vivo engendre estratégias, opções e articule decisões. No entanto, do estado saudável ao patológico não se dão apenas distintas mensurações quantitativas, como se o patológico fosse apenas uma variante do fisiológico: na doença, a potencialidade de normar-se de um ser vivo é efetivamente rebaixada, constrangida. perdendo dinamismo de superação. Há, sim. uma distinção qualitativa, vital, entre tais situações: "O estado patológico não é um simples prolongamento, quantitativamente variado, do estado fisiológico, mas é totalmente diferente" 12

Canguilhem combate, com tal posição, a leitura teórica tradicional desde o século XIX - Comte, Bernard -, que associava saúde e doença e as distinguia apenas no que tange a seus elementos quantitativos. Em que pese a importância da ciência desse periodo para afastar as pretensas dicotomias entre o natural e o "antinatural" ou o "mal", convertendo-os todos à mesma mensuração da natureza, tal movimento faz perder de vista que o saber e o agir médicos se orientam por um incômodo real, da doença, que é algo distinto de um viver saudável. Por conta da doença é que se há de construir um saber a respeito da saúde. ${ }^{13} \mathrm{~A}$ perspectiva de Canguilhem se baseará, então, no fato de uma separação qualitativa entre o estado de saúde e de doença, com esta revelando a ausência

\footnotetext{
10 "Leriche a renouvelé les problèmes relatifs à l'essence et au sens de la douleur, en ébranlant - sinon en renversant - le dogme de sa spécificité sensorielle. [...] À ne pas séparer l'expérimentation de l'intervention opératoire, Leriche parvient à une conscience exacte de leur carcatère commun de perturbation. La recherche est une technique et la technique est une altération de son objet." CANGUILHEM, Georges. La pensée de René Leriche. OEuvres complètes. Vol. IV. Résistance, philosophie biologique et histoire des sciences (1940-1965). Paris: Vrin, 2015, p. 723, 725

11 Gilbert Simondon, orientado diretamente por Canguilhem em sua formação universitária, desenvolve uma particular filosofia sobre a técnica em obras como Do modo de existência dos objetos técnicos. Cf. SIMONDON. Gilbert. El modo de existencia de los objetos técnicos. Buenos Aires: Prometeo, 2013. Ainda: "Simondon cruza de modo particular o dinamismo bergsoniano com a ideia canguilhemiana da criatividade da técnica. Ele traz à luz uma dinâmica cujo modo de manifestação privilegiado dá-se na criação técnica, como dimensão da imaginação, ou seja, como imaginação em diversos niveis potenciais. A filosofia simondoniana integra a linhagem daqueles que procuravam mostrar - antes da configuração das ciências do século XX - como a percepção do ser vivo em seu meio não é passiva, mas antecipação da ação por meio de conjuntos sensório-motores previamente estruturados que 'cortam' a matéria segundo os limites da ação possivel". CAMOLEZI, Marcos. Sobre o conceito de invenção em Gilbert Simondon. In: Scientiae Studia, São Paulo, v. 13, n. 2, 2015, p. 445. 12 CANGUILHEM, O normal e o patológico, op. cit., p. 52.

13 "Segundo Aristóteles, qualquer ciência procede do espanto. Essa afirmação se aplica também à fisiologia. Porém o espanto verdadeiramente vital é a angústia suscitada pela doença", Ibid., p. 61
} 
daquela. Não sendo uma mera mensuração, a patologia é tomada a partir do doente, que sente em si o incômodo de uma situação que se tornou inferior àquela anteriormente experimentada. ${ }^{14}$ O estado de doença é algo necessariamente distinto, em termos situacionais e experienciais, em face do estado saudável.

Daí, dado que a diferença entre elas não se apresenta no reducionismo a uma fixação quantitativa, a investigação de Canguilhem se volta à identificação da saúde e da doença no nivel da qualidade de ambas, no que se encaminhará, então, para a questão do normal, da normação da vida. Em termos de diferença qualitativa entre a saúde e a doença, seu núcleo reside na condição normativa que os individuos podem se dar em estados saudáveis - fisiológicos - ou doentes - patológicos. A saúde e a doença revelam normatividades distintas e específicas.

Quando chega a uma análise da saúde como normal, Canguilhem estabelecerá um contraste com os saberes médicos e sociais tradicionais, que, se tratavam a saúde como o normal, tratavam e a doença como o anormal. Tal leitura de mundo estipulava, científica ou quantitativamente, o padrão "correto", "apropriado", médio ou geral da saúde, para daí estabelecer seus vários contrastes, que constituiriam o patológico. Essa leitura é positivista, determinista, necessariamente idealista, porque trabalha com métricas almejadas ou alheias à experiência da vida. Contra a dicotomia entre o normal e o anormal, Canguilhem insistirá apenas em uma normatividade inexorável a todos os viventes, ${ }^{15}$ e suas variações qualitativas conforme o saudável e o doente, banindo a chave do anormal da filosofia da saúde.

Na perspectiva filosófica de Canguilhem, há uma relação entre vida e norma. O normal é um estado de normatividade a que o indivíduo se atribui e que o configura, impondo-se uma dinâmica reveladora de um impulso vital. ${ }^{16}$ Viver é normar-se. Porque se sente que tudo vai bem, a saúde se dá quando a possibilidade de normação não se destaca no transcorrer comum da existência. Ocorre que normatividade, havida na saúde, é de algum outro modo também possivel na doença. O patológico não é ausente de normatividade: possui, sim, uma modalidade de normatividade inferior. São clássicas as afirmações de Canguilhem a respeito:

Devemos dizer que o estado patológico ou anormal não é consequência da ausência de qualquer norma. A doença é ainda uma norma de vida, mas uma norma inferior, no sentido que não tolera nenhum desvio das condições em que é válida, por ser incapaz de se transformar em outra norma. O ser vivo doente está normalizado em condições bem definidas, e perdeu a capacidade normativa, a capacidade de instituir normas diferentes em condições diferentes. ${ }^{17}$

A doença se revela então, em Canguilhem, como o surgimento de uma nova ordem vital. Há - por conta do estado anterior saudável cuja ordem fisiológica deixou de existir - um contraste resultante de uma nova condição, patológica, que se lhe sucedeu. Esta, no entanto, jamais é uma desordem: representa, sim, uma nova ordem, mas indesejada, insuportável, negativa pois. Tampouco se há de falar que a doença seja uma anormalidade: não se trata da ausência de norma, mas de outra norma de vida.

Se não é a doença uma ausência de normas, e, sim, uma normatividade inferior àquela da saúde. há aqui envolvida sempre uma comparação, uma relação temporal. No entanto, há casos em que não se pode dizer de uma perda comparativa

\footnotetext{
14 "Achamos que não há nada na ciência que antes não tenha aparecido na consciência e que, especialmente no caso que nos interessa é o ponto de vista do doente que, no fundo, é verdadeiro", Ibid., p. 54 (grifo do autor).

15 "É a vida em si mesma, e não a apreciação médica, que faz do normal biológico um conceito de valor, e não um conceito de realidade estatística", Ibid., p. 84.

16 "A norma, em última instância, é sempre individual. Cada indivíduo tem a sua própria concepção de normalidade. A normalidade deixa de se restringir a um único padrão, deixa de ser conforme um modelo predefinido de saúde e passa a se expressar de diferentes formas. [...] Na relação com o meio, o ser vivo, ao invés de apenas sofrer influências, procura uma situação na qual recolhe as influências que correspondem às suas exigências. Ele estrutura seu meio. O meio do ser vivo é também obra do ser vivo que se furta ou se oferece a certas influências". COELHO, Maria Thereza Ávila Dantas; ALMEIDA FILHO, Naomar de. Análise do conceito de saúde a partir da epistemologia de Canguilhem e Foucault. In: GOLDENBERG, P.; MARSIGLIA, R. M. G.; GOMES, M. H. A. (org.). O clássico e o novo: tendências, objetos e abordagens em ciências sociais e saúde. Rio de Janeiro: Ed. Fiocruz, 2003. p. 108.

17 CANGUILHEM, O normal e o patológico, op. cit., p. 127.
} 
de qualidade vital, sendo a anomalia o seu mais distintivo exemplo. $\mathrm{Na}$ anomalia, o individuo, desde o nascimento ou desde o início da função corporal a que corresponde tal estado, tem seu comportamento já determinado por tais especificidades estruturais. Decorre, daí, que o indivíduo, quando se compara a si próprio, não encontra distinção na relação entre um estado anterior e um estado novo. A situação anômala, sendo condição estrutural daquela vida, não permite traçar a percepção de uma perda de normatividade. característica da doença. A anomalia, portanto, não pode ser considerada a assunção de uma patologia, mas de uma condição própria. De outro lado, a doença, advinda de um fluxo no qual um estado saudável se inferioriza, revela sempre uma perda de uma potência vital anterior.

Canguilhem propõe que a anomalia seja pensada como uma distinção entre seres nos quais, nessa comparação de um com o outro, não haja entre si uma substituição completa. O anômalo é específico, diverso, mas, aponta Canguilhem, diversidade não é doença, de tal sorte que a anomalia não é patológica. Por sua vez, a doença se revela pelo sentimento de vida contrariada, a ela sim se referindo tal pathos, o que leva, então, a corresponder doença com patologia. Com base nesta proposição, a anomalia é uma diferença entre indivíduos - uma variação espacial. A doença, uma diferença entre condições de um mesmo indivíduo - uma variação temporal.

Uma outra razão para não confundir anomalia e doença é que a atenção humana não é sensibilizada por uma e por outra por desvios da mesma espécie. A anomalia se manifesta na multiplicidade espacial; a doença, na sucessão cronológica. O próprio da doença é vir interromper o curso de algo, é ser verdadeiramente crítica. Mesmo quando a doença torna-se crônica, depois de ter sido crítica, há sempre um 'passado' do qual o paciente ou aqueles que o cercam guardam certa nostalgia. Portanto, a pessoa é doente não apenas em relação aos outros, mas em relação a si mesma. É o que ocorre na pneumonia, na arterite, na ciática, na afasia, na nefrite etc. É próprio da anomalia ser constitucional, congênita, mesmo se aparece depois do nascimento e só se manifesta ao iniciar-se o exercício da respectiva função, por exemplo, na luxação congênita do quadril. O portador de uma anomalia não pode, portanto, ser comparado a si mesmo. ${ }^{18}$

De modo vulgar, e quiçá reiterado, confundemse as anomalias com as anormalidades, ${ }^{19}$ aplicando aí a mesma leitura tradicional da diferença entre a doença e a saúde como quantidades distintas. Nesse sentido, tender-se-ia a dizer que a anomalia é rara, menos frequente que o estado dito normal. Canguilhem, em $O$ normal e o patológico, investe até mesmo em uma reflexão sobre a possibilidade de considerar um corpo "médio" ou dito em plenitude de órgãos e funções. Se se toma a evolução das espécies, a anomalia não é menos nem a plenitude já alcançada é o máximo quando consideradas em dinâmica a partir da multiplicidade de individuos de cada espécie. A anomalia é tão só distinta, e tal distinção pode, inclusive, revelar futuras funções adaptativas, algumas quiçá até melhores em termos de sobrevivência ou reprodução da espécie, de tal sorte que não se pode dizer que os corpos tenham um estado ideal a partir do qual o anômalo fosse necessariamente um doente. ${ }^{20}$

Tomando-se tais critérios, a anomalia, por não ser diferença em sucessão para o indivíduo que a porta, não é patologia. E no mesmo diapasão que dissocia a anomalia da anormalidade, como para Canguilhem normatividades acompanham tanto a saúde quanto a doença, não como variações de quantidade, mas, sim, como distintas qualidades da vitalidade, superior e inferior, então a associação entre a doença e a anormalidade só pode ser

\footnotetext{
18 Ibid. p. 91.

19 Canguilhem aponta para as raizes etimológicas distintas entre anomalia, sendo em grego an-omalos irregular, desigual, e anormal, do grego a-nomos, sem norma. As línguas ocidentais modernas tenderam a aproximar os conceitos no uso frequente, mas são originalmente distintos e guardam até hoje tal divergência. A anomalia não se refere a ausência de normas nem a perda de capacidade normativa, mas a uma distribuição irregular no seio da espécie, ibid., p. 85

20 "Na medida em que seres vivos se afastam do tipo específico, serão eles anormais que estão colocando em perigo a forma específica, ou serão inventores a caminho de novas formas? Conforme sejamos fixistas ou transformistas, consideraremos de modo diferente um ser vivo portador de um caráter novo. [...] A espécie seria o agrupamento de indivíduos, todos diferentes em certo grau, e cuja unidade traduz a normalização momentânea de suas relações com o meio, inclusive com as outras espécies, como Darwin tinha compreendido muito bem. 0 ser vivo e o meio, considerados separadamente, não são normais, porém é sua relação que os torna normais um para o outro", Ibid., p. 93 , 95.
} 
feita de modo relativo, em comparação com a normatividade de uma dada situação. Tomando-a em comparação à saúde como o normal, a patologia não é o anormal, e sim outra normalização, inferior.21

Havendo normatividades vitais tanto na saúde quanto na doença, para Canguilhem, o saudável se apresenta como possibilidade de abusar das normas e de instaurar novas normas. As contingências que demandam alterações nas condições normais, as mudanças de hábitos, os esforços incomuns, os constrangimentos mais extremos e as sobrecargas, tudo isso revela a saúde quando esse complexo encontra, da parte do indivíduo, mecanismos de normatividade distintos, ampliados, abusados:

Ser sadio significa não apenas ser normal em uma situação determinada, mas ser também, normativo, nessa situação e em outras situações eventuais. O que caracteriza a saúde é a possibilidade de ultrapassar a norma que define o normal momentâneo, a possibilidade de tolerar infrações à norma habitual e de instituir normas novas em situações novas. [...]

O homem sadio não foge diante dos problemas causados pelas alterações às vezes súbitas - de seus hábitos, mesmo em termos fisiológicos; ele mede sua saúde pela capacidade de superar as crises orgânicas para instaurar uma nova ordem.

O homem só se sente em boa saúde que é, precisamente, a saúde - quando se sente mais do que normal, isto é, não apenas adaptado ao meio e às suas exigências, mas, também, normativo, capaz de seguir novas normas de vida. ${ }^{22}$

É no sentido de saúde como potencial de abusar da própria disposição de normação de si e de capacidade de enfrentar as infidelidades do meio - as circunstâncias e acontecimentos como abertos ao ser que vive em um mundo de acidentes possiveis - que Canguilhem chega a reconhecer a saúde como um conjunto de seguranças e seguros, ensejando a possibilidade de reações. Sendo a doença uma redução da margem de tolerância às infidelidades do meio, o aspecto qualitativo de distinção entre saudável e patológico aqui se torna claro: "cada doença reduz o poder de enfrentar as outras, gasta o seguro biológico inicial sem o qual não haveria nem mesmo a vida".23

Sendo o patológico um normal, ainda que inferior, disso decorre que entre o normal e o patológico, então, não há uma distinção que se possa estabelecer a partir da dedução de termos gerais ou coletivos. A tendência a fixar uma métrica da saúde e da doença não resiste às circunstâncias e às situações comparativas e sucessivas dos individuos tomados em relação aos demais e, em especial, em relação a si próprios. O patológico e o normal se regem não pelo indice de normalidade ideal e sua ausência, como se fosse um jogo de sim e não. Sua concreta existência se dá a partir de uma dinâmica, com a potência de normas vitais que exsurgem das variadas situações. Não há normalidade absoluta (o que pressuporia um estado "ideal" ou "médio" da saúde), mas, sim, normatividade vital.

Nesse sentido, Canguilhem afasta o normal, necessariamente, do conceito de média. Para a tradição e para a fisiologia, há uma aproximação entre o normal e a média. A partir de variadas amostras, poder-se-iam, nessa visão comum, alcançar médias aritméticas ou frequências estatísticas, o que ensejaria, daí, parâmetros ditos normais de saúde. Trata-se de uma operação caricatural, que desconhece a realidade vital dos indivíduos, suas variadas circunstâncias e as situações histórico-sociais que lhes constrangem. ${ }^{24}$

O horizonte filosófico de Canguilhem descortina um entendimento complexo de vitalidade, jungido à medida de sua normatividade que, estando submetida às determinações do meio, também se

\footnotetext{
${ }^{21}$ 'Não podemos dizer que o conceito de 'patológico' seja o contraditório lógico do conceito de 'normal', pois a vida no estado patológico não é ausência de normas, mas presença de outras normas. Com todo rigor, 'patológico' é o contrário vital de 'são' e não o contraditório lógico de normal". CANGUILHEM, Georges. O conhecimento da vida. Rio de Janeiro: Forense Universitária, 2012, p. 182.

22 CANGUILHEM, O normal e o patológico, op. cit., p. 138, 141.

23 Ibid., p. 140

24 "Em resumo, achamos que se devem considerar os conceitos de norma e de média como dois conceitos diferentes que nos parece inútil tentar reduzir à unidade por meio da anulação da originalidade do primeiro. Parece-nos que a fisiologia tem mais a fazer do que procurar definir objetivamente o normal: deve reconhecer a normatividade original da vida. O verdadeiro papel da fisiologia, suficientemente importante e difícil, consistiria então em determinar exatamente o conteúdo das normas dentro das quais a vida conseguiu se estabilizar. sem prejulgar a possibilidade ou a impossibilidade de uma eventual correção dessas normas". Ibid., p. 123.
} 
levanta em relação ao próprio meio e ao organismo.25

A vitalidade, a partir de padrões variados, passa pelo individuo e suas capacidades, mas vai além, remetendo a potências biológicas. A normatividade, assim, é tanto uma estratégia do organismo - e/ ou do individuo em termos sociais - mas, ainda e estruturalmente, uma normatividade biológica. ${ }^{26}$

Com isso, pode-se ver, em Canguilhem, uma dúplice atividade normativa operando sobre saúde e patologia. ${ }^{27}$ Uma delas, um esforço do sujeito por normar-se, ajustar-se, adaptar-se, reagir, resistir, enfrentar ou combater novas situações. Mas, de outro lado, necessariamente, uma espécie de normatividade vital que se funda em uma dinâmica biológica, em uma constante relação com a polaridade dinâmica da vida. ${ }^{28}$ Neste aspecto, de uma normatividade biológica, Canguilhem aponta para uma normatividade inconsciente:

Achamos, ao contrário, que, para um ser vivo, o fato de reagir por uma doença a uma lesão, a uma infestação. a uma anarquia funcional, traduz um fato fundamental: é que a vida não é indiferente às condições nas quais ela é possivel, que a vida é polaridade e. por isso mesmo, posição inconsciente de valor, em resumo, que a vida é, de fato, uma atividade normativa. ${ }^{29}$

A normatividade vital se relaciona com a saúde e a patologia de tal modo que a medicina não pode estabelecer, genérica ou indiferentemente, parâmetros ou guias científicos de cura. No pensamento de Canguilhem, curar não é alcançar uma métrica-padrão, e, ainda nem é restabelecer as mesmas condições biológicas anteriores do individuo, sendo, sim, um processo de reconquista de estabilidade das normas fisiológicas: "curar é criar para si novas normas de vida, às vezes superiores às antigas. Há uma irreversibilidade da normatividade biológica". $3^{\circ}$ Afirmando postulados de Kurt Goldstein, Georges Canguilhem aponta ao fato de que a vida não admite reversibilidade. A doença, sendo uma limitação do potencial normativo do indivíduo, não será curada com a volta a um estado igual ao anterior. Na verdade, darse-ão reparações que podem ser, muitas vezes, a construção de verdadeiras inovações fisiológicas. ${ }^{31}$

Por não se revelar a cura como um processo indiferente ao ser, nem um restabelecimento idealmente exato das condições fisiológicas originárias, mas uma nova normatividade, daí, então, a saúde e a patologia, muito mais que objetos da ciência, estão jungidas à clínica, e esta à terapêutica. Nas palavras de Canguilhem:

Em matéria de patologia, a primeira palavra, historicamente falando, e a última palavra, logicamente falando. cabem à clínica. Ora, a clínica não é uma ciência e jamais o será, mesmo que utilize meios cuja eficácia seja cada vez mais garantida cientificamente. A clinica é inseparável da terapêutica, e a terapêutica é uma técnica de instauração ou de restauração do normal, cujo fim escapa à jurisdição do saber objetivo. pois é a satisfação subjetiva de saber que uma norma está instaurada. ${ }^{32}$

25 "Viver é valorizar os objetos e as circunstâncias de sua experiência, é preferir e excluir meios, situações, movimentos. A vida é o contrário de uma relação de indiferença com o meio". CANGUILHEM, George. "Vida". In: Veritas, Porto Alegre, v. 60, n. 2, 2015. p. 270.

26 "É por referência à polaridade dinâmica da vida que se podem chamar de normais determinados tipos ou funções. Se existem normas biológicas, é porque a vida, sendo não apenas submissão ao meio mas também instituição de seu próprio meio, estabelece, por isso mesmo, valores, não apenas no meio, mas também no próprio organismo. É o que chamamos de normatividade biológica". CANGUILHEM, O normal e o patológico, op. cit., p. 165.

${ }_{27}$ "A biopolítica que podemos derivar de Canguilhem será necessariamente política que visa garantir as condições para a experiência dessa paradoxal processualidade do vivente: uma biopolítica da mobilidade normativa". SAFATLE, Vladimir. "Uma certa latitude: Georges Canguilhem, biopolítica e vida como errância". In: Scientiae Studia, São Paulo, v. 13, n. 2, 2015, p. 359.

${ }_{28}$ "A capacidade normativa medeia a possibilidade de o ser vivo, em tensão com o meio, criar uma nova ordem fisiológica ou patológica. O vivo apresentaria uma posição inconsciente de valor ao exercer seu mais básico metabolismo como as funções de assimilação e excreção. Essa característica é que demarcaria a especificidade das ciências da vida em relação às ciências da natureza - a física e a química. A normatividade vital se apresenta como um dado que a ciência da vida não pode desconsiderar ao perseguir seu caráter de veracidade e sua vocação operacional. Esse é o grande problema que ressalta a tensão entre ciência e filosofia na epistemologia de Canguilhem". CZERESNIA, Dina. Categoria vida: reflexões para uma nova biologia. São Paulo e Rio de Janeiro: Ed. Unesp e Fiocruz, 2012, p. 69. 29 CANGUILHEM, O normal e o patológico, op. cit., p. 80.

$30 \quad$ Ibid., p. 166

31 "A vida não conhece a reversibilidade. No entanto, apesar de não admitir restabelecimentos, a vida admite reparações que são realmente inovações fisiológicas", Ibid., p. 138. Ainda no mesmo tema, mas em outro diapasão, abre-se, em Canguilhem, a reflexão sobre a inovação tecnológica na própria biologia: "Considerando a técnica como um fenômeno biológico universal, e não mais apenas como uma operação intelectual do homem, somos levados, de um lado, a afirmar a autonomia criadora das artes e dos ofícios em relação a todo conhecimento capaz de se os anexar para neles se aplicar ou de os informar para multiplicar-lhes os efeitos e, por conseguinte, de outro lado, inscrever o mecânico no orgânico". CANGUILHEM, O conhecimento da vida, op. cit., p. 137. Cf., ainda, HACKING, lan. Canguilhem parmi les cyborgs. In: BRAUNSTEIN, Jean-François (org.). Canguilhem: histoire des sciences et politique du vivant. Paris: PUF, 2007, p. 113, 141.

32 CANGUILHEM, O normal e o patológico, op. cit., p. 164 
Dando primazia à clínica em face de uma pretensa objetividade de métricas olímpicas da saúde, Canguilhem aproxima-se, de algum modo, de uma perspectiva aristotélica acerca do ato de clinicar e da terapêutica como artesanatos técnicos, saberes-fazeres artísticos que se assemelham à vida, em um contexto similar ao de Hipócrates. Em Ideologia e racionalidade nas ciências da vida. aponta para tal característica: "Aristóteles concebe a natureza e a vida como a arte das artes. [...] O naturalismo biológico de Aristóteles, que era filho de médico, assemelha-se ao naturalismo hipocrático". 33 Do mesmo modo, tal aristotelismo de fundo, no que tange à primazia da clínica na saúde, alcança até mesmo outro aspecto correlato, o da própria relação entre órgão e organismo. Sem ser aristotélico no campo de apontamento de causas finais à natureza, Canguilhem aproxima, no entanto, os órgãos do organismo no que tange à sua preservação ou à da espécie. ${ }^{34}$

A reflexão de Canguilhem, em O normal e o patológico, avança para discutir a própria natureza da fisiologia, que, tida como ciência que estuda os fenômenos da vida fundando-se em invariantes e constantes, na verdade não encontra a vida como uma realidade idêntica a si mesma, mas como um movimento polarizado. Isto porque, para Canguilhem, a fisiologia, bem como as ciências da vida, como as que envolvem a saúde, não se apresentam como mera positividade à disposição de análises métricas, nem como algo que apareça como definição ou índice genérico suficiente para deduzir-se em casos concretos. A saúde se revela em sua ausência, a partir dos incômodos advindos do estado patológico. Por isso, a saúde só pode ser compreendida pela sua negatividade:

São os insucessos da vida que chamam - e que sempre chamaram - a atenção para a vida. Todo conhecimento tem origem na reflexão sobre um insucesso da vida. Isso não significa que a ciência seja uma receita dos processos de ação. mas, ao contrário, que o progresso da ciência supõe um obstáculo à ação. É a própria vida, pela diferença que estabelece entre seus comportamentos propulsivos e seus comportamentos repulsivos, que introduz na consciência humana as categorias de saúde e de doença. Essas categorias são biologicamente técnicas e subjetivas, e não biologicamente científicas e objetivas. Os seres vivos preferem a saúde à doença. O médico tomou, explicitamente. o partido do ser vivo; ele está a serviço da vida, e é a polaridade dinâmica da vida que ele expressa, quando fala em normal e patológico. ${ }^{35}$

As ciências da vida, como a fisiologia, não surgem nem se fundam em uma analítica olímpica de uma saúde pretensamente tida como o saudável. A fisiologia se erigiu por conta dos doentes que reclamam o médico em razão de suas doenças, demandando-lhes esforços de atuação e compreensão. ${ }^{36} \mathrm{~A}$ saúde se revela por sua negatividade, passando pelo indivíduo doente a dimensão do saudável e do patológico. A saúde. então, se apresenta mais pela clínica do que. propriamente, por uma medicina tida por catálogo da saúde ou subsunção a critérios genéricos de saúde e doença. Não é a mera informação técnica ou laboratorial padronizada que revela a patologia. A técnica e a ciência se relacionam com a doença pela clínica e pela vitalidade. ${ }^{37}$

\footnotetext{
CANGUILHEM, Ideologia e racionalidade nas ciências da vida, op. cit., p. 110
}

"Canguilhem associait intimement la téléologie à la vie. De ce point de vue, on peut le voir comme se plaçant dans la lignée aristotélicienne. Sa téléologie n'était pas de celles qui expliquent l'existence des organismes par leurs buts, mais une téléologie dans laquelle on pouvait comprendre un aspect d'un organisme, ou d'un organe, en considérant seulement la raison pour laquelle cet organe était fait, quel but il servait, soit dans la vie, soit dans la préservation de l'organisme ou de son espèce". HACKING, "Canguilhem parmi les cyborgs", op. cit., p. 116. 35 CANGUILHEM, O normal e o patológico, op. cit., p. 160.

36 "Foi a experiência de um obstáculo, vivida primeiro por um homem concreto, sob a forma de doença, que suscitou a patologia em seus dois aspectos, de semiologia clínica e de interpretação fisiológica dos sintomas. Se não houvesse obstáculos patológicos, não haveria também fisiologia, pois não haveria problemas fisiológicos a resolver", Ibid., p. 149

37 "Tanto a política quanto a tecnologia funcionariam inseridas na sociedade humana como próteses ou prolongamento de órgãos vitais, cuja função atesta sua ligação primeira com a vida, pois a função de regulação que esses órgãos prolongados contêm é primeiro de tudo uma função vital por excelência. Assim, a tecnologia não é o corolário da ciência, mas da vida - tanto quanto a política". LABREA, Vanessa Nicola: MADARASZ, Norman Roland. Organismo e função reguladora: determinações do vivo em Georges Canguilhem. Veritas, Porto Alegre, V. 60, n. 2, 2015, p. 261. Ainda: "En 1943. Canguilhem concebia la técnica como estrategia vital, en contraposición a la ciencia. [...] En 1963-1966, Canguilhem vuelve a pensar la ciência, por el contrario, en relación directa con la vida. Este cambio de perspectiva se puede atribuir a dos razones diferentes. En primer lugar, en 1966, el autor ya no piensa la vida a partir de lo vital sino a partir de lo social. [...] En segundo lugar. los conceptos de la biología moderna - sentido, información, error - aparecen como estruturaciones internas de lo viviente. Asi, la ciencia genera um nuevo cariz de la vida". LE BLANC, Guillaume. Canguilhem y las normas. Buenos Aires: Nueva Visión, 2004, p. 91, 93. 
A patologia não é empírica, como se fora um dado a ser esquadrinhado, mas vital, dinâmica, relacional. ${ }^{38}$ Por tal razão, para Canguilhem, a doença não está em um órgão isolado, apto a ser analisado cientificamente. É medicamente incorreto falar em órgãos doentes, tecidos doentes, células doentes. Só cabe tratar da doença a partir do todo de um servivo. "A doença é um comportamento de valor negativo para um ser vivo individual, concreto, em relação de atividade polarizada com seu meio. Nesse sentido, não é apenas para o homem, mas para qualquer ser vivo, que só existe doença do todo orgânico",39

\section{O normal e o social}

A originalidade do pensamento de Canguilhem repousa no deslocamento da questão da saúde do plano de uma analítica de quantificação para o da distinção qualitativa entre saúde e doença. Se, antes dele, pensadores como Comte e Bernard objetivavam uma saída das metafísicas que acreditavam ser a doença um antinatural, Canguilhem vai mais longe, inscrevendo uma imanência da saúde e da doença não apenas em uma compreensão de que são comumente naturais - um postulado de positivismo científico - mas, sim, arraigando as normatividades vitais em bases materiais. ${ }^{40}$ Tratando de experiências que são necessariamente individuais, para as quais a clínica se orienta, o escopo de Canguilhem é o de afastar todo idealismo de deduções da saúde a partir de parâmetros abstratos ou funcionais e, mesmo, todo tecnicismo que apontaria a métricas médias, gerais ou impessoais a respeito. Nessa ordem de encontro da materialidade da normação da vida, o pensamento de Canguilhem ocasiona imediatos impactos político-sociais, como quando promove a dissociação entre a doença e a anormalidade, restituindo, ainda, à anomalia e à monstruosidade, ainda que com suas peculiaridades, a condição de normalidade natural.41

A normação vital, que se faz de modo particular nos variados individuos de cada espécie e distinto entre eles nos casos chamados de anomalia, e que se faz distinta cronologicamente em cada individuo nos casos de saúde e doença, é compreendida, por Canguilhem, como propulsão dinâmica do indivíduo. Ocorre que tal normatividade da saúde é tanto vital, biológica, mas também relacional, situacional, histórica e social, atravessada por saberes científicos e práticas, de onde também se impõem e se extraem implicações político-sociais, em um complexo entremeado e de distintas origens e imposições. ${ }^{42} \mathrm{O}$ complexo da polaridade vital se faz, portanto, com amálgamas de normações tanto biológicas quanto sociais. ${ }^{43}$

Se a normatividade vital não se dá em sentido absoluto, como objeto à disposição de métricas,

\footnotetext{
${ }_{38}$ "On s'oriente aussi vers une conception plus relationelle que substantielle ou essentialiste de la santé et de la maladie dans la mesure où la capacité normative de l'individu s'enracine pour Canguilhem dans la relation qu'il a avec son milieu". GIROUX, Élodie. Après Canguilhem: definir la santé et la maladie. Paris: PUF, 2010, p. 30

39 CANGUILHEM, O normal e o patológico, op. cit., p. 161.

$40 \quad$ "A materialidade do vivo conta menos do que o fluxo que passa através dela. É esta matéria 'desmaterializada' que, do ponto de vista epistemológico, torna não só uma ciência da vida possivel, mas também o vitalismo de Canguilhem". PORTOCARRERO, Vera. As ciências da vida: de Canguilhem a Foucault. Rio de Janeiro: Ed. Fiocruz, 2009, p. 138.

${ }_{41} \quad$ Canguilhem aponta o problema histórico da questão: "É aqui que surge a questão espinhosa das relações entre a monstruosidade e o monstruoso. Eles são uma dualidade de conceitos da mesma cepa etimológica. Eles estão a serviço de duas formas do julgamento normativo, médico e jurídico, inicialmente confundidas, mais do que compostas, no pensamento religioso, progressivamente abstratas e laicizadas". Combatendo tal horizonte, asseverará: "A vida não transgride nem suas leis, nem seus planos de estrutura. Nela, os acidentes não são exceções e não há nada de monstruoso nas monstruosidades". CANGUILHEM, O conhecimento da vida, op. cit., p. 190, 201. Cf., ainda, DELAPORTE, François. Foucault, Canguilhem et les monstres. In: BRAUNSTEIN, Jean-François (org.). Canguilhem: histoire des sciences et politique du vivant. Paris: PUF, 2007, p. 91-112.

42 "I tre poli normativi - la normatività del vivente, la normatività scientifica e la normatività storica - rinviano l'uno all'altro, senza fondersi né ridursi l'uno nell'altro. La confusione dei tre oggetti (naturale, scientifico e storico) e soprattutto del livello della normatività vitale com quello dela normatività scientifica spinge ad un'esportazione impropria di metodo (dal piano scientifico a quello storico) e produce un risultato 'ideologico', nel senso canguilhemiano". VAGELLI, Matteo. Canguilhem e le ideologie storiografiche. In: LUPI, Fiorenza; PILOTTO, Stefano (org.). Infrangere le norme. Vita, scienza e tecnica nel pensiero di Georges Canguilhem. Milão: Mimesis, 2019. p. 72.

43 "O 'sofrimento' enquanto fato que deve ser submetido a um cuidado clínico depende de disposições normativas variáveis de acordo com contextos sócio-históricos. Sofre-se da mesma maneira, dá-se o mesmo sentido ao sofrimento independentemente do contexto sócio-histórico? Se nossa resposta for negativa, então é possível que a 'significação do sofrimento psíquico' seja uma questão eminentemente politica, já que diz respeito à maneira com que os corpos sofrerão interferências, os comportamentos serão normatizados, os processos de socialização e de reprodução dos modos de vida serão defendidos. Ou seja, diz respeito à maneira com que a 'saúde' aparece como categoria fundamental de imposição de uma normatividade social à vida". SAFATLE, Vladimir. O que é uma normatividade vital? Saúde e doença a partir de Georges Canguilhem. Scientiae Studia, São Paulo, v. 9. n. 1, 2011, p. 12.
} 
só podendo se estabelecer em relação com situações determinadas, ${ }^{44}$ decorre daí, portanto, que estruturas de vida, modelos de dinâmica social, formas de trabalho, meio natural e social, tecnologia, tomados em totalidade, é que forjarão a saúde. São conhecidas as palavras de Canguilhem a respeito:

O homem, mesmo sob o aspecto físico, não se limita a seu organismo. O homem, tendo prolongado seus órgãos por meio de instrumentos, considera seu corpo apenas como um meio de todos os meios de ação possiveis. É, portanto, para além do corpo que é preciso olhar, para julgar o que é normal ou patológico para esse mesmo corpo. Com uma enfermidade como o astigmatismo ou a miopia, um indivíduo seria normal em uma sociedade agricola ou pastoril, mas seria anormal na marinha ou na aviação. Ora, a partir do momento que a humanidade ampliou tecnicamente seus meios de locomoção, saber que certas atividades nos são vedadas faz com que nos sintamos anormais, pois essas atividades se tornaram, para a espécie humana, ao mesmo tempo uma necessidade e um ideal. Portanto, só se compreende bem que, nos meios próprios do homem, o mesmo homem seja, em momentos diferentes, normal ou anormal, tendo os mesmos órgãos. se compreendermos como a vitalidade orgânica se desenvolve em plasticidade técnica e em ânsia de dominar o meio. 45

Canguilhem procede a mais do que uma simples aproximação entre biologia e sociedade. ${ }^{46}$ A questão da saúde não se apresenta apenas como um dado biológico a ser relacionado, eventual e externamente, com condições sociais, mas, sim, como uma imbricação estrutural do biológico e do social. A reflexão sobre a saúde e a vida, mesmo pelo ângulo da técnica médica, é social:
As prescrições do bom-senso médico são tão familiares que nelas não se procura nenhum sentido profundo. E, no entanto, é aflitivo e dificil obedecer ao médico que diz: "Poupe-se!". "É fácil dizer para eu me cuidar, mas tenho minha casa para cuidar", dizia, por ocasião de uma consulta no hospital, uma dona de casa que não tinha nenhuma intenção irônica ou semântica ao dizer esta frase. Uma família significa a eventualidade do marido ou de um filho doente, da calça rasgada que é preciso remendar à noite. quando o menino está na cama, já que ele só tem uma calça, de ir longe comprar pão se a padaria próxima estiver fechada por infração aos dispositivos regulamentares etc. Cuidar-se... como é difícil, quando se vivia sem saber a que horas se comia, sem saber se a escada era ingreme ou não, sem saber o horário do último bonde porque, se a hora tivesse passado, voltava-se a pé para casa, mesmo que fosse longe. 47

Dominique Lecourt, tratando da natureza da norma no pensamento filosófico acerca da medicina, faz eco a tal posição de Georges Canguilhem sobre a relação complexa entre normatividade vital do paciente e dinâmica de imposição social de uma norma biológica definidora da saúde:

Os médicos podem, sem se trair, prestar a sua ajuda aos empreendimentos de normatização dos comportamentos e dos espíritos, pela imposição de uma concepção mesquinha da vida como simples conservação do perfil médio de um ser individual encerrado na parte orgânica de si mesmo? Tememos então que a antiga aliança da doença e do mal da qual Hipócrates havia começado a se livrar não venha de novo a se fortalecer sob nossos olhos, em nome da ciência! A revolta ou o desespero já levam mais de um, entre os jovens, a escolher a loucura, a morte ou a toxicomania nas formas mais concretas, as mais trági-

\footnotetext{
44 "A noção de normalidade, aplicada a esta experiência, não pode designar um conteúdo objetivo unilateralmente positivo, e assim oferecido diretamente, como um objeto dado, a uma racionalização científica, assumindo diretamente a forma de uma medida, ou seja, de uma determinação em termos quantitativos das condições desta normalidade, regida então pela representação de uma média. $\dot{E}$ recusado, assim, o postulado positivista que tende a neutralizar a diferença entre o normal e o patológico conduzindo o patológico a não ser mais que uma forma, ou um grau do normal, considerado em termos de mais ou de menos, em nome de um principio elementar segundo o qual só há ciência do que pode ser medido, princípio que encontraria aqui seus derradeiros requisitos no que podemos denominar um otimismo tecnológico. Se há uma experiência do vivo, esta se efetua e se faz conhecer - e reconhecer - por meio da ativa recusa de uma atitude de indiferença ou de indiferenciação quanto à essencial diferença que, do seu próprio interior, constitui esta experiência". MACHEREY, Pierre. Georges Canguilhem, um estilo de pensamento. Goiânia: Almeida \& Clément, 2010, p. 58.

45 CANGUILHEM, O normal e o patológico, op. cit., p. 143.

46 "O nómos da filosofia biológica deverá ser buscado nesses modos de existência. E tais modos de existência configuram-se sempre a partir de injunções impostas pelo meio. O meio, por essa via, constitui uma espécie de a priori do vivo e é a partir das injunções postas por ele ao 'conhecimento da vida' que a filosofia biológica deverá elaborar e constantemente reconstruir a metafísica que tal conhecimento merece". ALMEIDA, Fábio F. de. Georges Canguilhem: vitalismo e filosofia biológica. In: ALMEIDA, Fábio F. de; SALOMON, Marlon (org.). De Bergson a Rancière: pensar a filosofia francesa do século XX. Goiânia: Ricochete, 2017. p. 93.
}

47 CANGUILHEM, O normal e o patológico, op. cit., p. 138, 139. 
cas do desafio à ciência dos médicos, simbolo, na sua opinião, de uma ordem social sufocante. ${ }^{48}$

O balanço do mais patente pensamento de Georges Canguilhem sobre a questão da normatividade social e a saúde foi alcançado com o texto que completa O normal e o patológico, "Novas reflexões referentes ao normal e ao patológico", da década de 1960. Aí, entram em cena as diretrizes externas àquelas do indivíduo, que operam em elevado grau a normatização da vida, impondose e demandando variadas e específicas reações normativas biológicas. ${ }^{49}$ Nesse momento, então, definitivamente, Canguilhem une as pontas de uma saúde biovital com uma saúde social. Dentre outros aportes, está ecoando nesta fase de seu pensamento, também, a novidade representada pelas proposições de seu orientando Michel Foucault. ${ }^{\circ}$

A preocupação de relacionar o vital com o social, no texto novo e derradeiro de O normal e o patológico, se faz a partir de um inventário filosófico que vai de pensadores como Kant a Bachelard, até mesmo passando por Kelsen e sua teoria pura do direito. Canguilhem retoma a noção de diferenciação entre norma social e norma da natureza. Ao contrário da normação natural, cuja determinação é impositiva, a norma social se apresenta como possibilidade. ${ }^{51}$ Assim sendo, a normação social aponta para um caminho que comporta alternativas, dado que o possível não é o inexorável. A postulação de Canguilhem se direciona a considerar que, de algum modo, a normalidade vital, mesmo estando sob leis naturais, tem polaridade, dinâmica e, por isso, possibilidade. O chamado anormal - na verdade normação em qualidade distinta - é uma vitalidade tão possivel quanto aquela que se convencionou chamar por normal. Exatamente pelo dito anormal existir é que ele impulsiona normações vitais contrárias, ditas normais. O projeto normativo da vida é derivado existencialmente das normações vitais qualitativamente indesejáveis. ${ }^{52}$

Para Canguilhem, no entanto, residem diferenças de fundo entre uma normação social e uma normação vital. A primeira, quando tomada em totalização, tende à organização. A segunda, por sua vez, perfaz um organismo vivo. Neste sentido, o social se faz por procuras por regulações sem uma finalidade intrínseca ou já dada. O vital, por sua vez, revela a existência de dispositivos de regulação. o meio interno e a homeostase oferecem. organicamente, polarizações que buscam retornar à constante quando ocorram variações. ${ }^{53}$ Daí, para Canguilhem, a dificuldade em intercambiar de

${ }_{48}$ LECOURT, Dominique. Normas. In: RUSSO, Marisa; CAPONI, Sandra (org.). Estudos de filosofia e história das ciências biomédicas. São Paulo: Discurso Editorial, 2006, p. 302.

49 "Dans les « Nouvelles réflexions », vingt ans plus tard, le conflit n'est plus entre les normes vitales et les normes du savoir mais entre une compréhension de la science qui au contraire le met em avant contre les diverses formes de neutralisation. Devant la réduction que le savoir risque d'opérer, la philosophie exprime l'irréductibilité des valeurs de la vie jusque dans la Science. La philosophie a alors moins pour rôle de faire parler le savoir que de référer le savoir à ce qu'un usage réducteur du savoir a pour vocation de taire et de cacher, le conflit normatif des valeurs présent jusque dans la volonté de savoir". LE BLANC, Guillaume. Le pluralisme des valeurs de la science chez Canguilhem. In: CASSOU-NOGUĖS, P.; GILLOT, P. (org.). Le concept, le sujet et la science: Cavaillès, Canguilhem, Foucault. Paris: Vrin, 2011, p. 107. 50 "Canguilhem também parece reconhecer a Foucault o mérito de ter excitado - ao menos pela demonstração a Canguilhem de seus próprios limites - parte das suas novas reflexões sobre o normal e o patológico, temas de cursos e publicações nos primeiros anos da década de 6o. Isso também ajuda a entender o recurso sistemático que, nos cursos sobre as ideologias médicas no século XIX, ministrados a partir do final daquela década, Canguilhem fazia aos livros Naissance de la clinique e Histoire de la folie à l'âge classique. Assim. embora não devamos minimizar a importância muito bem documentada que os livros e as lições de Canguilhem tiveram para o desenvolvimento da pesquisa de Foucault, o melhor é tratá-los como interlocutores, que mantiveram relações de crítica (ainda que raras). de repetição e de reforço mútuo. O problema da normalização e o conceito de biopoder ilustram bem o caso, especialmente quando consideramos, também, os cursos de Foucault ao longo da década de 70". ALMEIDA, Tiago Santos. Canguilhem e a gênese do possível: estudo sobre a historicização das ciências. São Paulo: LiberArs, 2018, p. 160.

51 Cf. MASCARO, Alysson Leandro. Introdução ao estudo do direito. São Paulo: GEN-Atlas, 2019, p. 77-89.

52 "O anormal, enquanto a-normal, é posterior à definição do normal, é a negação lógica deste. No entanto, é a anterioridade histórica do futuro anormal que provoca uma intenção normativa. O normal é o efeito obtido pela execução do projeto normativo, é a norma manifestada no fato. Do ponto de vista do fato há, portanto, uma relação de exclusão entre o normal e o anormal. Essa negação, porém, está subordinada à operação de negação, à correção reclamada pela anormalidade. Não há, portanto, nenhum paradoxo em dizer que o anormal, que logicamente é o segundo, é existencialmente o primeiro". CANGUILHEM, O normal e o patológico, op. cit., p. 193.

53 "A regulação social tende, portanto, para a regulação orgânica e a imita, mas nem por isso deixa de ser composta mecanicamente. Para poder identificar a composição social com o organismo social, no sentido próprio desse termo, seria preciso poder falar nas necessidades e normas de uma sociedade como se fala nas necessidades e normas de vida de um organismo, isto é, sem sombra de ambiguidades. As necessidades e normas da vida de um lagarto ou de um carapau em seu habitat natural se exprimem pelo próprio fato de esses animais estarem naturalmente vivos nesse habitat. Mas basta que um individuo questione as necessidades e as normas dessa sociedade e as conteste - sinal de que essas necessidades e normas não são as de toda a sociedade - para que se perceba até que ponto a necessidade social não é imanente, até que ponto a norma social não é interna, até que ponto, afinal das contas, a sociedade, sede de dissidências contidas ou de antagonismos latentes, está longe de se colocar como um todo". Ibid., p. 205. 
modo simples os conceitos de saúde e doença do vital para o social, dada a natureza distinta da organização social e do organismo vivo. ${ }^{54}$

Também leituras sociais mais avançadas, como a do marxismo contemporâneo, a partir de Althusser, ao trabalharem com a reprodução social, o fazem a partir de normações sociais, mas sem considerar a sociedade um organismo com homeostase. Se se pode mesmo infirmar que sociedades de exploração específica como a capitalista se estruturam na falha, na contradição, no antagonismo e na luta, e, nesse contexto, a reprodução social se erige como crise ${ }^{55}$, o social se assenta, então, de modo distinto daquele do corpo biológico, cuja normação vital ao mesmo tempo se levanta das e impõe as regulações. Neste mesmo diapasão, o projeto de Canguilhem, ao fundar-se no vital - sem confundi-lo nem com uma total redução a um normativismo social nem com um mecanicismo de uma natureza só atenta a um causal empirista -, consegue estabelecer. junto com o marxismo, um afastamento das leituras cientificistas que intentam esquadrinhar a saúde em uma espécie de analítica quantitativa. Assim, Adriana Belmonte Moreira:

Se Canguilhem adere à tradição médico-filosófica vitalista não é somente por compartilhar com ela o reconhecimento da originalidade do fenômeno vital. É também porque ela, ao contrário da tradição mecanicista, opõe-se à ideologia de controle da natureza, sustentada pela ciência moderna. Aqui a noção de ideologia aparece no sentido marxista o qual, na leitura de Canguilhem, que acompanha a de Althusser, é um conceito que se aplica aos sistemas de representações que se exprimem na linguagem da política, da moral, da religião e da metafísica e que se apresentam como se fossem a expressão do que são as próprias coisas, enquanto são de fato meios de proteção e defesa de um determinado sistema de relações dos homens entre si e dos homens com as coisas. Portanto. se Canguilhem não vê problema em ser chamado de vitalista, é, sobretudo. porque ele encontra no vitalismo uma ética de respeito e defesa da vida, que irá embasar sua postura ético-política de contraposição a uma ideologia de domínio da vida, que encontrou no nazifascismo sua versão mais acabada. ${ }^{56}$

A leitura do vital e do social nas normações por Canguilhem chega, por fim, à discussão sobre o pretenso erro biológico. O estudo dos distúrbios bioquímicos hereditários, propulsionado em especial pelo avanço da genética, enseja, no século XX, a consideração de uma natureza falha, o que geraria, em decorrência, a possibilidade de uma correção da própria natureza, propiciada pelos avanços científicos da própria genética. Nesse quadro, em que se aponta para o erro e a antecipação do sofrimento dos corpos que pudessem se constituir em qualidade de normatividade vital diminuida - eugenia Canguilhem contrapõe cautelas que relembram a variabilidade genética da vida como forma inclusive de potenciar suas normações e, em especial, uma tolerância diante da variedade. ${ }^{57}$ Tais cautelas - quase aristotélicas de meio-termo - encaminham a preocupação de Canguilhem para o fato de que o desejo de uma saúde total, sem contato com a doença, gera ao seu modo uma paradoxal doença da incapacidade do ser vivo em estar apto à adaptação conforme as distintas situações, pois que "a ameaça da doença é um dos elementos constitutivos da saúde". ${ }^{8}$ O projeto da saúde é o lançar-se tanto à determinação quanto ao aleatório da vida.

\footnotetext{
54 "Canguilhem himself suggests that there are complicated relations between the social and the biological, with society both organism and machine. Social regulation has parallels with organic regulation, but also with the idea of organization, a designed system for control and order". ELDEN, Stuart. Canguilhem. Medford: Polity Press, 2019, p. 33.

55 Cf. ALTHUSSER, Louis. Sobre a reprodução. Petrópolis, Vozes, 2008. MASCARO. Alysson Leandro. Estado e forma política. São Paulo: Boitempo, 2013. MASCARO, Alysson Leandro. Crise e golpe. São Paulo: Boitempo, 2018.

56 MOREIRA. Adriana Belmonte. Clínica e resistência: contribuições da racionalidade vitalista de Canguilhem ao campo da saúde. São Paulo, Scientiae Studia, 2019, p. 19.

57 "Na origem desse sonho, há a intenção generosa de poupar a seres vivos inocentes e impotentes o peso atroz de representar os erros da vida. Na meta de chegada desse sonho, encontra-se a polícia dos genes, encoberta pela ciência dos geneticistas. No entanto, não se deve deduzir dai a obrigação de adotar uma permissividade genética, mas apenas a obrigação de relembrar à consciência médica que sonhar com remédios absolutos é, muitas vezes, sonhar com remédios piores que o mal". CANGUILHEM, O normal e o patológico, op. cit., p. 228.

58 Ibid., p. 234
} 


\section{Referências}

ALMEIDA, Fábio F. de. Georges Canguilhem: vitalismo e filosofia biológica. In: ALMEIDA, Fábio F. de: SALOMON, Marlon (org.). De Bergson a Rancière: pensar a filosofia francesa do século XX. Goiânia: Ricochete, 2017

ALMEIDA, Tiago Santos. Canguilhem e a gênese do possivel: estudo sobre a historicização das ciências. São Paulo: LiberArs, 2018

ALTHUSSER, Louis. Sobre a reprodução. Petrópolis: Vozes, 2008.

BERNARD, Claude. Introduction à l'étude de la médecine expérimentale. Paris: Flammarion, 2010.

CAMOLEZI, Marcos. Sobre o conceito de invenção em Gilbert Simondon. Scientiae Studia, São Paulo, v.13, n. 2, 2015. https://doi.org/10.1590/S167831662015000200010 .

CANGUILHEM, George. Vida. Veritas, Porto Alegre, v. 60, n. 2, 2015. https://doi.org/10.15448/19846746.2015.2.22005.

CANGUILHEM, Georges. La pensée de René Leriche. In: CANGUILHEM, Georges. OEuvres complètes: Résistance, philosophie biologique et histoire des sciences (1940-1965). Paris: Vrin, 2015. t. 4.

CANGUILHEM, Georges. Le fascisme et les paysans. In: CANGUILHEM, Georges. OEuvres complètes: Écrits philosophiques et politiques (1926-1939). Paris: Vrin, 2011. t. 1.

CANGUILHEM, Georges. Ideologia e racionalidade nas ciências da vida. Lisboa: Edições 70, 1977.

CANGUILHEM, Georges. O conhecimento da vida. Rio de Janeiro: Forense Universitária, 2012.

CANGUILHEM, Georges. O normal e o patológico. Rio de Janeiro: Forense Universitária, 2015.

CARRION, Rejane. A ideologia médico-social no sistema de A. Comte. Porto Alegre: IFCH-UFRGS, 1977.

COELHO, Maria Thereza Ávila Dantas; ALMEIDA FILHO, Naomar de. Análise do conceito de saúde a partir da epistemologia de Canguilhem e Foucault. In: GOLDENBERG, P.; MARSIGLIA, R. M. G.; GOMES, M. H. A. (org.). O clássico e o novo: tendências, objetos e abordagens em ciências sociais e saúde. Rio de Janeiro: Ed. Fiocruz, 2003.

COELHO, Ruy. Individuo e sociedade na teoria de Auguste Comte. São Paulo: Perspectiva e CESA, 2005.

CZERESNIA, Dina. Categoria vida: reflexões para uma nova biologia. São Paulo: Ed. Unesp; Rio de Janeiro: Fiocruz, 2012.

DELAPORTE, François. Foucault, Canguilhem et les monstres. In: BRAUNSTEIN, Jean-François (org.). Canguilhem: histoire des sciences et politique du vivant. Paris : PUF, 2007. https://doi.org/10.3917/puf. braun.2007.01.0091.
DUTRA, Luiz Henrique de Araújo. Claude Bernard, o vitalismo e o materialismo. In: RUSSO, Marisa; CAPONI, Sandra (org.). Estudos de filosofia e história das ciências biomédicas. São Paulo: Discurso Editorial, 2006.

ELDEN, Stuart. Canguilhem. Medford: Polity Press, 2019.

GIROUX, Élodie. Après Canguilhem: definir la santé et la maladie. Paris: PUF, 2010. https://doi.org/10.3917/ puf.girou.2010.01.

HACKING, Ian. Canguilhem parmi les cyborgs. In: BRAUNSTEIN, Jean-François (org.). Canguilhem: histoire des sciences et politique du vivant. Paris: PUF, 2007. https://doi.org/10.3917/puf.braun.2007.01.0113.

LABREA, Vanessa Nicola; MADARASZ, Norman Roland. Organismo e função reguladora: determinações do vivo em Georges Canguilhem. Veritas, Porto Alegre, v. 60, n. 2, 2015. https://doi. org/10.15448/1984-6746.2015.2.21869.

LE BLANC, Guillaume. Le pluralisme des valeurs de la science chez Canguilhem. In: CASSOU-NOGUES, P.; GILLOT, P. (org.). Le concept, le sujet et la science: Cavaillès, Canguilhem, Foucault. Paris: Vrin, 2011.

LE BLANC, Guillaume. Canguilhem y las normas. Buenos Aires: Nueva Visión, 2004.

LECOURT, Dominique. Normas. In: RUSSO, Marisa: CAPONI, Sandra (org.). Estudos de filosofia e história das ciências biomédicas. São Paulo: Discurso Editorial, 2006.

LECOURT, Dominique. Georges Canguilhem. Paris: PUF, 2008.

LERICHE, René. L'idée de l'Homme dans la thérapeutiquz. In: CLARKE, Robert (org.). René Leriche ou l'humanisme en chirurgie. Paris: Seghers, 1962.

MACHEREY, Pierre. Georges Canguilhem, um estilo de pensamento. Goiânia: Almeida \& Clément, 2010.

MASCARO, Alysson Leandro. Crise e golpe. São Paulo: Boitempo, 2018.

MASCARO, Alysson Leandro. Estado e forma politica. São Paulo: Boitempo, 2013

MASCARO, Alysson Leandro. Introdução ao estudo do direito. São Paulo: GEN-Atlas, 2019.

MOREIRA, Adriana Belmonte. Clínica e resistência: contribuições da racionalidade vitalista de Canguilhem ao campo da saúde. São Paulo: Scientiae Studia, 2019.

PORTOCARRERO, Vera. As ciências da vida: de Canguilhem a Foucault. Rio de Janeiro: Ed. Fiocruz, 2009. https://doi.org/10.7476/9788575414101.

SAFATLE, Vladimir. O que é uma normatividade vital? Saúde e doença a partir de Georges Canguilhem. Scientiae Studia. São Paulo, v. 9, n. 1, 2011.

SAFATLE, Vladimir. Uma certa latitude: Georges Canguilhem, biopolítica e vida como errância. Scientiae Studia. São Paulo, v. 13, n. 2, 2015. https://doi. org/10.1590/S1678-31662015000200005.

SIMONDON, Gilbert. El modo de existencia de los objetos técnicos. Buenos Aires: Prometeo, 2013. 
VAGELLI, Matteo. Canguilhem e le ideologie storiografiche. In: LUPI, Fiorenza; PILOTTO, Stefano (org.).

Infrangere le norme. Vita, scienza e tecnica nel pensiero di Georges Canguilhem. Milão: Mimesis, 2019.

\section{Alysson Leandro Mascaro}

Professor da Faculdade de Direito da Universidade de São Paulo (USP, São Paulo, SP, Brasil). Doutor e Livre-Docente em Filosofia e Teoria Geral do Direito pela USP.

\section{Endereço para correspondência}

Largo de São Francisco, 95 - Edifício Anexo I - $2^{\circ}$ andar $01005-010$

São Paulo, SP, Brasil 